\title{
Modular training as technology of professional skills development of mechanical engineers
}

\author{
Shamshina Irina ${ }^{\text {la }}$ \\ ${ }^{1}$ Far Eastern Federal University (FEFU), Kuznecova, 74-7, Vladivostok, 690013, Russia
}

\begin{abstract}
There are main provisions of modular training program by «Theory of Automatic Control" for students of technical universities is treating. Analyze of advantages and disadvantages of modular training system in comparison with the traditional system in the formation of future engineers' professional skills. Detection of changes in the level of learning, basic skills and motivational sphere of students en-rolled in the modular training program.
\end{abstract}

Keywords. Modular training; professional skills; individual cumulative index.

\section{Introduction}

A formation and development professional skill of future expert is one of the main tendencies of modern higher education development. On the other hand, development of professional skills in students of technical universities presents one of low-developed, but especially important directions in the increase of educational process efficiency and quality of specialists training. We made an attempt to substantiate theoretically and experimentally prove possibility of the most important professional abilities development in future mechanical engineers in the conditions of modular training.

\section{Theoretical principles}

We consider activity of the engineer as creative, i.e. the engineer has to possess creative abilities which essence consists in find new, unique (from a set of alternative options), the solution of a task (project) which isn't contradicting conditions of production on the basis of modern knowledge.

\footnotetext{
${ }^{a}$ Corresponding author: I_G_SH@mail.ru 
There are three steps of creative abilities:

- The basic - we understand such abilities which make a technical aspect of creative activity of the engineer

- The professional - professional skills directly related to the professional activity of engineer

- The highest - skills first of all associated with the character of thinking and its most general laws that lie outside the usual professional activity

List of basic skills necessary for the work of a mechanical engineer, is quite diverse. Based on questionnaire related to professional activities conducted among professionals who have experience of 4 to 40 years, we have allocated four most important of them: 1) The ability to articulate the goal of work; 2) the ability to find the missing data and convert units of measurement; 3) the ability to calculate, evaluate the result and find a "dropping out" digits; 4) the ability to synthesize the system and is technically competent to explain the result.

\section{Ascertaining stage of the experiment}

For diagnostics of initial level of professional abilities for 102 mechanic students $\mathrm{s}$ it was offered to perform the settlement and graphic task (SGT) on the main subjects which assessment was made by V.P. Bespalko's criteria: the 1st level - recognition; the 2nd level - reproduction; the 3rd level - application. On the basis of this task's performance results students were divided into three conditional groups:

The I group - students with the low level of basic abilities formation.

The II group - students have the average level of basic abilities formation.

The III group - students have high level of basic abilities formation.

Table 1 shows the results of expert assessment of the basic skills of the students.

Table 1. Expert assessment of the level of basic skills formation

\begin{tabular}{llll}
\hline Skills & \multicolumn{3}{c}{ Level \% } \\
\cline { 2 - 4 } & high & average & low \\
\hline $\begin{array}{l}\text { 1. To make a work's goals } \\
\begin{array}{l}\text { 2. Find out missing dates and make unit } \\
\text { conversion }\end{array}\end{array}$ & 20,59 & 38,24 & 41,18 \\
$\begin{array}{l}\text { 3. Calculate, evaluate the result and find a } \\
\text { "dropping out" digit }\end{array}$ & 8,82 & 52,96 & 23,53 \\
$\begin{array}{l}\text { 4. Synthesize system and technically competent } \\
\text { explain the results }\end{array}$ & 11,76 & 38,24 & 52,94 \\
\hline
\end{tabular}

Thus, clearly make goals of work could only 21 students (20.59\%), 39 (38.24\%) didn't understand task clearly, and 42 students $(41.18 \%)$ did not have any idea about what is It required from them. Possess ability to find missing data and to translate units of measure at the high and low level on 24 persons $(23,53 \%)$, on an average - $54(52,94 \%)$. To make calculation, to estimate the received result and find the "dropping-out" digits on high levels could only 9 students $(8,82 \%)$, on an average - 39 people $(38,24 \%)$, on low - $54(52,94 \%)$. Ability to synthesize system and technically competently to explain the received result at the high level 12 students $(11,76 \%)$, on an average - $48(47,06 \%)$, on low - 42 possess 
$(41,18$ It is interesting to note that one of the listed abilities only at 6 people $(5,88 \%)$ clearly expressed, and also at 6 people $(5,88 \%)$ all four skills are expressed clearly.

After analysing the composition of the mistakes made by students in the performance calculation and graphic tasks, we concluded that the students usually do not ask, what in the end they should have, cannot move received prior knowledge to new conditions, to use reference books, to evaluate the result.

Thus, results of the carried-out diagnostic task showed that at students - participants of experiment - basic abilities are developed at quite low level and demand further improvement.

\section{The main principles of the module training program}

Informative activity of the student by itself doesn't arise; it is result of the contents and methods of training - active, intensive and problem. But what methods wouldn't be applied, it is important to create such psychology and pedagogical conditions in which the student can take an active personal position and fully prove as the subject of educational activity.

The program of modular training is also based on these principles and includes the following basic provisions:

- Fragmentation a course of discipline into separate components - modules

- Synthetic character of lectures

- Teacher gives lectures in the problematic character of the main sections of the course

- Division of educational group into small groups (on 5 people), it's a professional task offer to each of them, for example, carrying out part of lecture or practical class in a certain subject

- Statement by the teacher during lectures and laboratory works of the questions demanding work with educational literature

- Carrying out various systematic control

- System of estimation of training results on the basis of an individual cumulative index

Division of the course "Theory of Automatic Control" into modules was carried out on the basis of the analysis and systematization of the maintenance of a training material by two principles: 1) logical structuring (from simple to difficult) and 2) functionality of the training content, i.e. an orientation of the didactic purpose on development of professional abilities.

In this regard in structure of the course "Theory of Automatic Control" we allocated three main functional modules (FM) of system and operational type: 1) the basic concepts and definitions in the field of ACT; 2) stability of linear systems and quality of management process; 3) Synthesis of automatic control systems.

\section{Checking stage of the experiment}

There were formed two groups of students: experimental group (34 person) and control group (34 person).

The analysis was carried out on the basis of multilevel engineering test tasks on I, II and to the III module of discipline, estimates for tasks and total examination estimates of students of experimental and traditional systems of training. Results of research are given in tables 2 and 3 . 
Table 2. Expert assessment of knowledge of students by the ACT course based on the tasks and exam

\begin{tabular}{|c|c|c|c|c|c|c|c|c|}
\hline \multirow[t]{2}{*}{ Score point } & \multicolumn{4}{|l|}{ Tasks } & \multicolumn{4}{|l|}{ Exam } \\
\hline & "3" & "4" & "5" & $\begin{array}{l}\text { average } \\
\text { score }\end{array}$ & "3" & "4" & $" 5 "$ & $\begin{array}{l}\text { average } \\
\text { score }\end{array}$ \\
\hline $\begin{array}{l}\text { Experimental } \\
\text { group, } \%\end{array}$ & 29,41 & 44,12 & 26,47 & 3,97 & 44,12 & 41,17 & 14,71 & 3,71 \\
\hline $\begin{array}{l}\text { Control group, } \\
\% \text { : }\end{array}$ & 61,76 & 29,41 & 8,82 & 3,47 & 70,59 & 23,53 & 5,88 & 3,35 \\
\hline
\end{tabular}

The analysis of results showed that the GPA for performance of RGZ and examination at students of experimental group is higher, than at students of control group. For a settlement and graphic task the assessment "3" was received by 10 students of EG (21 students of KG), "4" - 15 (respectively 10) students, "5" - 9 (respectively 3) students. Estimates for examination were distributed as follows: "3" - 15 in EG (24 in KG), "4" - 14 (8), "5" - 5 (2) respectively.

Table 3. Expert assessment of students' knowledge on the basis of multi-level engineering test assignments

\begin{tabular}{|c|c|c|c|c|c|c|c|c|c|c|c|c|}
\hline \multirow[t]{2}{*}{ Level of task } & \multicolumn{4}{|c|}{ I module } & \multicolumn{4}{|c|}{ II module } & \multicolumn{4}{|c|}{ III module } \\
\hline & 1 & 2 & 3 & 4 & 1 & 2 & 3 & 4 & 1 & 2 & 3 & 4 \\
\hline $\begin{array}{l}\text { Experimental } \\
\text { group, } \%\end{array}$ & 35,3 & 29,4 & 26,5 & 8,8 & 23,5 & 20,6 & 41,2 & 14,7 & 17,7 & 23,5 & 35,3 & 23,5 \\
\hline $\begin{array}{l}\text { Control } \\
\text { group, \% }\end{array}$ & 67,7 & 26,5 & 5,88 & - & 58,8 & 23,5 & 14,7 & 2,94 & 50 & 29,4 & 17,7 & 2,94 \\
\hline
\end{tabular}

The analysis of results showed that in experimental group upon transition from the module to the module positive dynamics of the decision by students of tasks on the more difficult level is observed. If during the 1st module test on the first level of difficulty have done by 12 people $(35.29 \%)$, then the module II - by $8(23.53 \%)$, and the III - only 6 $(17.65 \%)$. At the same time increased the number of students who have completed the task of the fourth level of difficulty from 3 persons $(8.82 \%)$ by the I module to $5(14.71 \%)$ and 8 $(23.53 \%)$, respectively by II and III module. It is observed positive dynamics in the control group.

Checking the level of basic skills development was conducted in accordance with the criteria developed by us the above. Expert judgment exhibited by the students performed computational and graphical task before and after the experiment. Results of the study are presented in Table 4.

Comparative analysis of expert estimations, the students of the experimental group exhibited prior to and after the experiment shows that in the course of the experiment the students is the development of all of the basic skills to a high enough level, however the greatest changes happened in the level of formation of abilities to formulate the work purposes, to find missing data and to translate units of measure. 
Table 4. Expert assessment of the level of formation of basic skills

\begin{tabular}{|c|c|c|c|c|c|c|}
\hline \multirow[t]{3}{*}{ Skills } & \multicolumn{6}{|c|}{ The level of formation } \\
\hline & \multicolumn{2}{|c|}{ I - recognition (low) } & \multicolumn{2}{|c|}{ II - reproduction (average) } & \multicolumn{2}{|c|}{ III - application (high) } \\
\hline & $\begin{array}{l}\text { Before } \\
\text { experiment }\end{array}$ & $\begin{array}{l}\text { After } \\
\text { experiment }\end{array}$ & $\begin{array}{l}\text { Before } \\
\text { experiment }\end{array}$ & $\begin{array}{l}\text { After } \\
\text { experiment }\end{array}$ & $\begin{array}{l}\text { Before } \\
\text { experiment }\end{array}$ & $\begin{array}{l}\text { After } \\
\text { experiment }\end{array}$ \\
\hline 1. To make a work's goals & $17,65 \%$ & - & $50 \%$ & $38,24 \%$ & $32,35 \%$ & $61,76 \%$ \\
\hline $\begin{array}{l}\text { 2. Find out missing dates and make unit } \\
\text { conversion }\end{array}$ & $14,71 \%$ & - & $50 \%$ & $20,59 \%$ & $35,29 \%$ & $79,41 \%$ \\
\hline $\begin{array}{l}\text { 3. Calculate, evaluate the result and find a } \\
\text { «dropping out» digit }\end{array}$ & $32,35 \%$ & $14,71 \%$ & $41,17 \%$ & $41,17 \%$ & $26,47 \%$ & $44,12 \%$ \\
\hline $\begin{array}{l}\text { 4. Synthesize system and technically } \\
\text { competent explain the results }\end{array}$ & $29,41 \%$ & $8,82 \%$ & $47,06 \%$ & $41,17 \%$ & $23,53 \%$ & $50 \%$ \\
\hline
\end{tabular}

\section{Conclusions}

Thus, the processing of the results of the experiment showed that the modular training program has a positive effect not only on the level of learning and the development of basic skills, but also on the formation of positive motivation to the teaching and professional activities, and on the emotions of students during class. These facts once again confirm the effectiveness of the proposed program of modular training - in our opinion the most promising directions in the field of rational construction of the educational process, combining operational and motivational aspects of the formation and development of professional skills.

\section{Reference}

1. Bespal'ko, V.P. (1989). The terms of educational technology. Moscow, 190. 